\title{
CLASSIFICAÇÁO DOS LODOS FORMADOS DURANTE O PROCESSO DE COAGULAÇÂO/FLOCULAÇÃO DA ÁGUA COM OS COAGULANTES PAC E MORINGA OLEIFERA
}

\author{
Cynthia Algayer da Silva ${ }^{1}$ \\ Carole Silveiral \\ Fernando Alves da Silval \\ Marcia Regina Fagundes Klen ${ }^{2}$ \\ Rosângela Bergamasco ${ }^{1}$
}

\begin{abstract}
Resumo - O processo de tratamento para produção de água potável gera resíduos em algumas etapas do processo de tratamento principalmente no decantador (lodo). Este lodo é formado durante o processo de coagulação/floculação, com o auxílio de coagulantes químicos (PAC- Policloreto de Alumínio) ou naturais (Moringa oleifera) que vêm sendo investigados intensamente. Pela ABNT NBR 10.004 este lodo é classificado como "resíduo sólido", portanto deve ser tratado e disposto conforme exigência dos órgãos reguladores. O objetivo deste trabalho foi classificar o lodo formado, no processo de coagulação/floculação, utilizando PAC e Moringa como coagulantes de acordo com o conjunto de normas ABNT NBR 10.004 ("Resíduos sólidos Classificação"), ABNT NBR 10.005 (Procedimentos para obtenção de extrato lixiviado de resíduos sólidos”) e ABNT NBR 10.006 ("Procedimentos para obtenção de extrato solubilizado de resíduos sólidos") segundo a análise de metais dos extratos lixiviado e solubilizado dos lodos. Os ensaios de lixiviação e solubilização dos lodos indicam que os lodos de PAC e Moringa são classificados como resíduos CLASSE II A, Não perigoso - Não inerte. Mesmo com o uso de um coagulante natural, o lodo pode possuir uma alta concentração de metais pesados em sua composição, pois estes possivelmente são oriundos da água bruta utilizada no tratamento. Portanto os lodos devem ser dispostos de modo adequado, de forma a não causar danos ao meio ambiente e aos seres humanos.
\end{abstract}

Palavras-chave: Lodo, coagulante natural, classificação, resíduos sólidos.

\begin{abstract}
The drinking-water treatment plants, generally, generates waste in some stages of the treatment, mainly in the settling vessel (sludge). This sludge is formed during the coagulation/flocculation stage, with aid of chemical coagulants (PAC - Poly Aluminium Chloride) or natural (Moringa oleifera) that currently are being intensively researched. According to ABNT NBR 10004 this sludge is classified as "solid waste" and therefore must be previously classified in order to be disposed of adequately. The classification of the sludge formed in coagulation/flocculation process, using PAC and Moringa as coagulant, is investigated. This was done according to the set of regulations ABNT NBR 10004 ("Solid Waste - Classification"), ABNT NBR 10005 ("Procedures for obtaining leached extract of solid waste") and ABNT NBR 10006 (2004) ("Procedures for obtaining soluble extract of solid waste") based on metals analysis of sludge leached and solubilized extract. The sludge leaching and solubilization tests indicate that PAC and Moringa sludge are classified as Class II A, non-hazardous and non-inert waste. Even with the use of a natural coagulant, the sludge can have a high concentration of heavy metals in its composition, as these are, probably, from raw water used in the treatment. Therefore, the sludge must be disposed adequately, as not to cause damage to the environment and humans.
\end{abstract}

Keywords: Sludge, natural coagulant, classification, solid waste.

\footnotetext{
1 Universidade Estadual de Maringá.

2 Universidade Estadual do Oeste do Paraná.
} 


\section{INTRODUÇÃO}

O processo de potabilização das águas naturais para abastecimento público tem como principal objetivo adequar a água bruta ao padrão de potabilidade vigente estabelecido pela Portaria 518 de 25 de Março de 2004 (Botero et al., 2009). A demanda por água potável e a péssima qualidade da água dos rios está exigindo o uso de maiores concentraçóes de produtos químicos no processo de tratamento da água bruta, gerando maior quantidade de resíduos, denominados lodos de Estação de Tratamento de Água (ETA) (Hoppen et al., 2006).

Uma das principais etapas deste processo é a etapa de coagulação/floculação, que consiste na remoção das impurezas (partículas em suspenção ou coloidais) da água, e para isso é necessário o auxílio de um coagulante, os mais comumente usados nas ETA's são o sulfato de alumínio e o policloreto de alumínio (PAC).

Existem atualmente muitos estudos que avaliam as vantagens da utilização de coagulantes naturais no tratamento de água (Cardoso et al., 2008; Bongiovani et al., 2010; Monaco et al., 2010). Um coagulante natural que vem sendo intensamente estudado, devido as suas propriedades coagulantes, é a semente de Moringa oleifera Lam. Segundo Davino (1976), a semente de Moringa possui uma proteína que provoca o mecanismo de coagulação/floculação na água de maneira análoga ao mecanismo provocado pelos polieletrólitos, que são polímeros provenientes de proteínas e polissacarídeos de origem sintética ou natural.

Os processos de potabilização da água bruta nas ETA's podem em diversas etapas gerar resíduos com as mais diferenciadas características. Os resíduos gerados no tratamento da água bruta são, principalmente, a água de lavagem de filtro e o lodo dos decantadores (Achon et al., 2008).

De acordo com a ABNT NBR 10.004 (2004) o lodo gerado no tratamento da água é classificado como "resíduo sólido", portanto deve ser tratado e disposto conforme exigência dos órgãos ambientais.

Há muito tempo, o destino dos resíduos de ETA vinha sendo os cursos d'água próximos das estaçôes, agregando a estes uma elevada carga poluidora (Reis et al., 2007). No entanto, a crescente preocupação e a regulamentação têm restringido ou proibido essa disposição. Esta prática tem sido questionada por órgáos ambientais devido aos riscos à saúde e ao meio ambiente.

Segundo Achon et al. (2008) devido aos efeitos diretos causados ao ambiente aquático do corpo receptor e danos à fauna aquática, o lançamento dos resíduos gerados em ETA's, em corpos d'água, pode ser considerado crime ambiental, de acordo com a Lei 9.605/98.

O objetivo deste trabalho é classificar os lodos formados durante o processo de coagulação/floculaçáo com o uso do coagulante químico (PAC) e o coagulante natural (Moringa) segundo o conjunto de normas brasileiras ABNT NBR $10.004,10.005$ e 10.006 (2004).

\section{MATERIAIS E MÉTODOS}

A classificaçáo do lodo foi efetuada em etapas assim definidas:

\section{PRIMEIRA ETAPA - PRODUÇÃO DO LODO:}

A água bruta utilizada foi a mesma captada no Rio Pirapó pela Companhia de Saneamento do Paraná - SANEPAR, e foi coletada na adutora de água bruta da Estação de Tratamento de Água da cidade de Maringá - PR.

Para a caracterização da água bruta foram realizadas as análises de cor aparente, turbidez, $\mathrm{pH}$, DQO, $\mathrm{DBO}_{5}$, sólidos suspensos, sólidos totais. Os metais presentes na água bruta foram analisados segundo a metodologia descrita por Standard Methods for the Examination of Water and Wastewater - Analytical Methods for Flame Spectroscopy (APHA, 1998). A quantificação dos metais foi realizada em um espectrofotômetro de Absorção Atômica Varian, Modelo Spectr AA. 10 plus (Figura 1).

Foram realizados ensaios de coagulaçáo/floculação em bateladas de 10 litros com o auxílio de um agitador mecânico para obtençáo do lodo. Foram utilizadas somente águas de alta cor e turbidez para obtenção de uma quantidade significativa de lodo para realização das análises.

Utilizou-se nos ensaios o coagulante químico Policloreto de Alumínio (PAC), e o coagulante natural Moringa oleifera Lam. Foram utilizadas nesta pesquisa sementes frescas de Moringa, provenientes da Universidade Federal de Sergipe UFS, o PAC utilizado foi doado pela SANEPAR de Maringá - PR. 


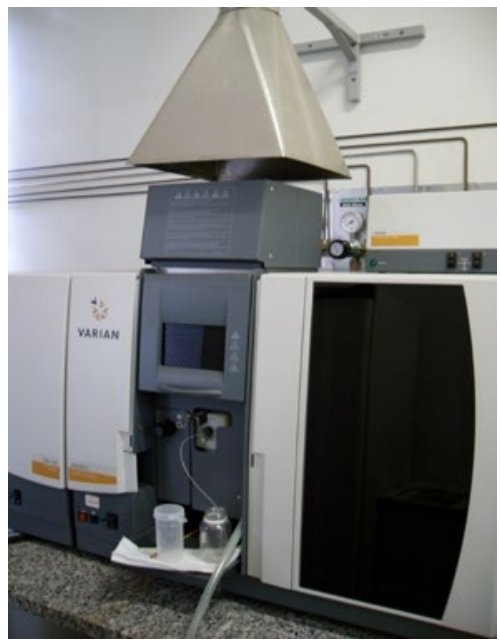

Figura 1 - Absorção Atômica Varian, Modelo Spectr AA. 10 plus.

As concentraçóes ótimas dos coagulantes usados foram determinadas em trabalhos desenvolvidos anteriormente. A concentração ótima para a Moringa foi determinadas por Madrona (2010), para o PAC foi determinada por Carvalho (2008).

As Tabelas 1 e 2 apresentam as condiçóes experimentais aplicadas no processo de produção dos lodos de PAC e Moringa.

Tabela 1 - Concentraçóes ótimas utilizadas no processo de coagulação/floculação.

\begin{tabular}{c|c|c}
\hline $\begin{array}{c}\text { Coagulante } \\
\text { aplicado }\end{array}$ & $\begin{array}{c}\text { Concentração } \\
\text { do coagulante }\end{array}$ & Fonte \\
\hline $\begin{array}{c}\text { PAC } \\
\text { Policloreto de } \\
\text { Alumínio) } 10 \% \\
\mathrm{v} / \mathrm{v}\end{array}$ & $80 \mathrm{mg} / \mathrm{L}$ & $\begin{array}{c}\text { CARVALHO } \\
(2008)\end{array}$ \\
\hline $\begin{array}{c}\text { Moringa } 1 \% \\
\mathrm{~m} / \mathrm{v} \mathrm{em} \mathrm{soluçâo} \\
\text { de } \mathrm{KCl} 1 \mathrm{~mol} / \mathrm{L}\end{array}$ & $175 \mathrm{mg} / \mathrm{L}$ & $\begin{array}{c}\text { MADRONA } \\
(2010)\end{array}$ \\
\hline
\end{tabular}

Tabela 2 - Condiçóes experimentais utilizadas no processo de coagulação/floculação.

\begin{tabular}{|c|c|c|c|c|}
\hline $\begin{array}{c}\text { Coagu- } \\
\text { lante } \\
\text { aplicado }\end{array}$ & Fonte & $\begin{array}{c}\text { Coagula- } \\
\text { çáo }(\mathrm{tmr})\end{array}$ & $\begin{array}{c}\text { Flocu- } \\
\text { laçáo } \\
(\mathrm{tml})\end{array}$ & $\begin{array}{c}\text { Decan- } \\
\text { taçáo }\end{array}$ \\
\hline \multirow{4}{*}{ PAC } & CAR- & $800 \mathrm{~s}^{-1}$ & $12 \mathrm{~s}^{-1}$ & $\mathrm{t}=\approx$ \\
& VALHO & $\mathrm{t}=\approx$ & $\mathrm{t}=\approx$ & $30 \mathrm{~min}$ \\
& $(2008)$ & $1 \mathrm{~min}$ & $26 \mathrm{~min}^{-1}$ & \\
\hline \multirow{4}{*}{ Moringa } & MA- & $100 \mathrm{~s}^{-1}$ & $10 \mathrm{~s}^{-1}$ & $\mathrm{t}=1$ \\
& DRONA & $\mathrm{t}=\approx$ & $\mathrm{t}=\approx$ & hora \\
& $(2010)$ & $3 \mathrm{~min}$ & $15 \mathrm{~min}$ & \\
\hline
\end{tabular}

Foi utilizado, no total das bateladas, em torno de 100 litros de água bruta com alta turbidez, por ensaio, para se obter uma quantidade significativa de lodo para realização das análises, tanto com o uso do coagulante químico quanto o coagulante natural na etapa de coagulação/floculação.

\section{SEGUNDA ETAPA - CLASSIFICAÇÃO DO LODO:}

Para a realização dos ensaios de classificação dos resíduos sólidos, as amostras de lodo foram desidratadas em estufa a $100^{\circ} \mathrm{C}$, até o lodo estar completamente seco, em seguida as amostras foram trituradas, utilizando um triturador de bancada TECNAL (Figura 2), a fim de se obter um tamanho de partícula inferior a $9,5 \mathrm{~mm}$, conforme estabelecido pelas normas citadas a seguir.

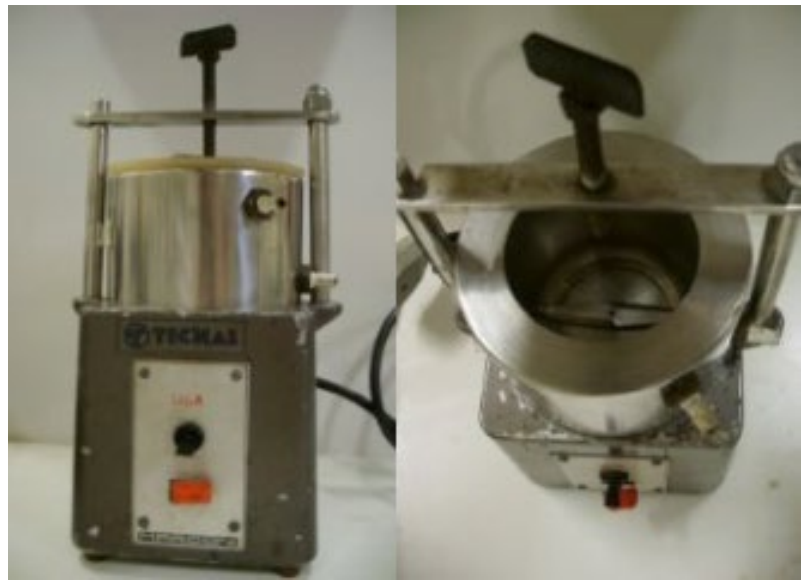

Figura 2 - Triturador de bancada (TECNAL).

A classificação dos resíduos sólidos foi realizada de acordo com a norma técnica ABNT NBR 10004 (2004) "Resíduos sólidos - Classificação", vinculada às duas outras normas: ABNT NBR 10005 (2004) "Procedimento para obtenção de extrato lixiviado de resíduos sólidos"; ABNT NBR 10006 (2004) "Procedimento para obtenção de extrato solubilizado de resíduos sólidos".

Os ensaios para a obtenção do extrato lixiviado foi realizado com o auxílio do equipamento Agitador Rotativo para Não Voláteis TE - 743 (TECNAL) conforme mostra a Figura 3, e para a obtenção do extrato solubilizado foi utilizado um agitador mecânico (Figura 4). 


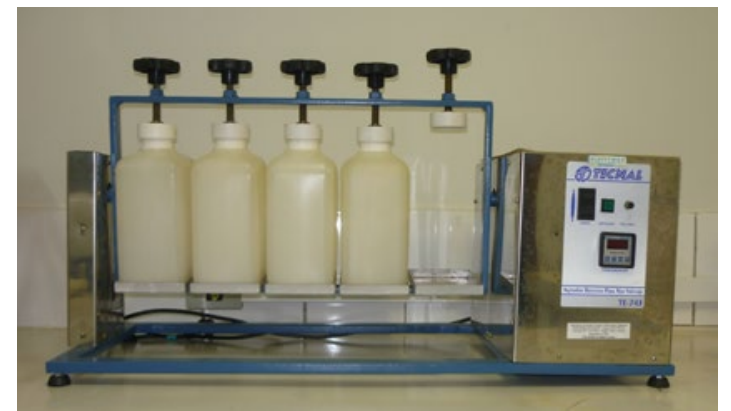

Figura 3 - Agitador Rotativo para Não Voláteis TE - 743 (TECNAL).

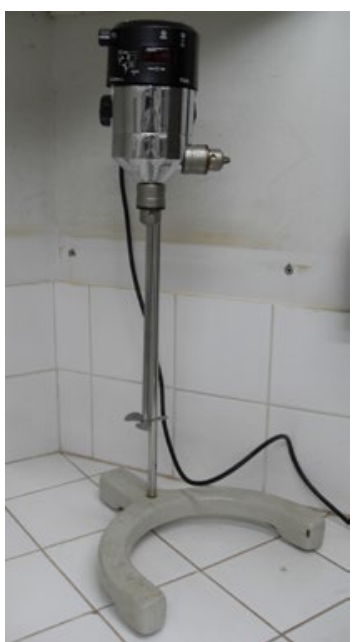

Figura 4 - Agitador mecânico.

Deste modo, a partir dos ensaios estabelecidos pela norma, os resíduos sólidos podem ser classificados e enquadrados nas seguintes categorias: Classe I - Resíduo perigoso e Classe II - Resíduo não perigoso, que é subdividida em Classe IIA - Não inertes e Classe IIB - Inertes.

A classificação dos resíduos sólidos envolve a identificaçáo do processo que os originou de seus constituintes e características, e a comparação destes constituintes com listagens de resíduos e substâncias cujo impacto à saúde e ao meio ambiente é conhecido.

Os resíduos, cujas características não podem ser prontamente avaliadas, foram analisados segundo o fluxograma de classificação de resíduos sólidos, de acordo com a análise de metais (Figura 5).

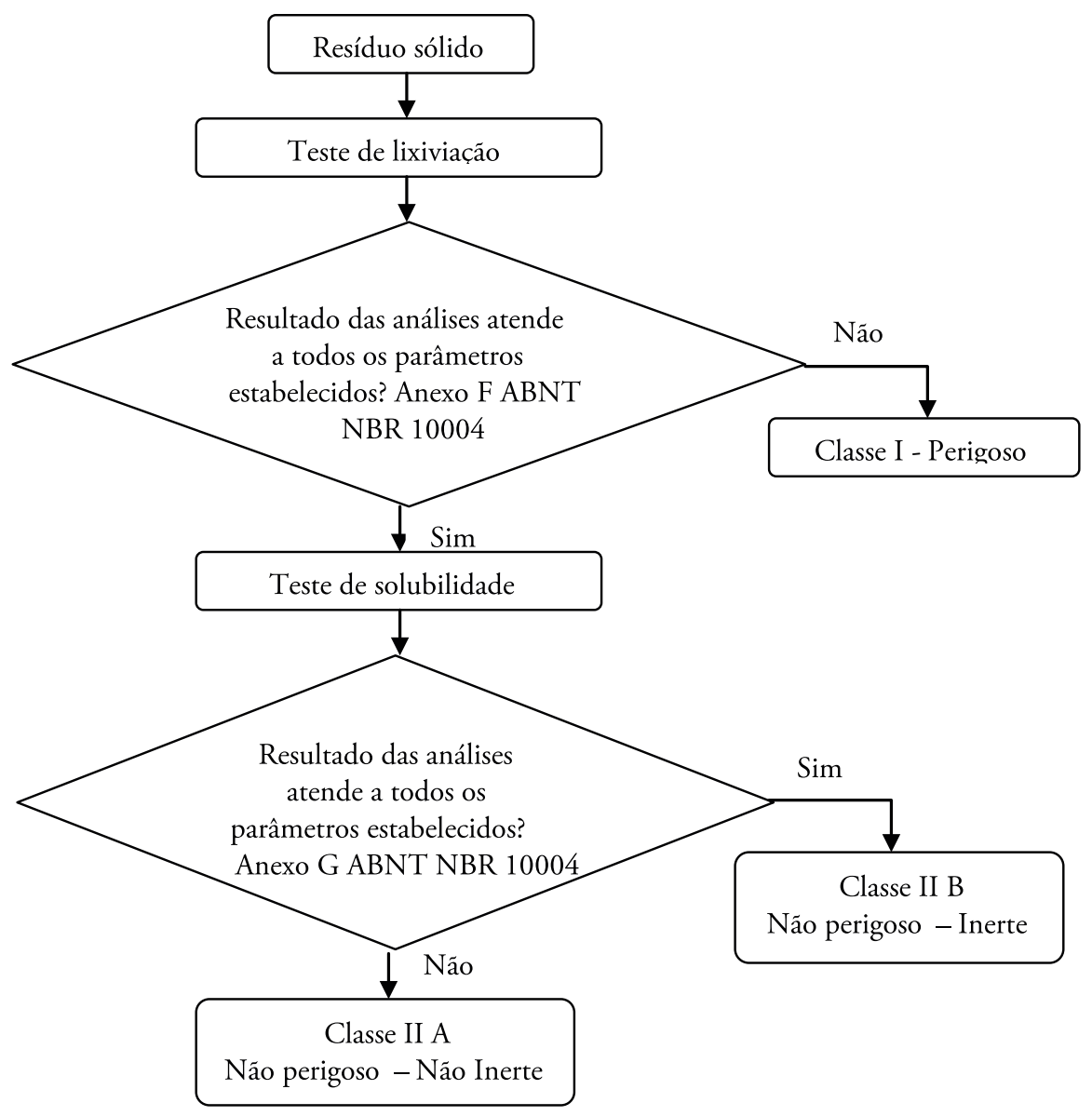

Figura 5 - Caracterização e classificação de resíduos sólidos.

Fonte: Adaptado da norma ABNT NBR 10004. 


\section{RESULTADOS E DISCUSSÁO}

Neste item serão apresentados os resultados referentes a caracterizaçáo do lodo e ao estudo dos metais na água bruta assim como o estudo do lixiviado e solubilizado dos lodos PAC e Moringa.

Os resultados serão apresentados como média e também como faixa dos valores (mínimo máximo) encontrados nas análises dos metais. Os resultados encontrados variam muito, pois mudam de acordo com a característica da água bruta utilizada no tratamento.

\section{CARACTERIZAÇÃO DA ÁGUA BRUTA}

A Tabela 3 apresenta os valores médios das características físico-químicas presentes na água bruta, que foi utilizada nos ensaios de coagulação/ floculação.

Tabela 3 - Valores médios para caracterização da água bruta.

\begin{tabular}{|l|c|c|}
\hline PARÂMETRO & Média & $\begin{array}{c}\text { Limite } \\
\text { CONAMA } \\
357 \text { (Classe } \\
3 \text { ) }\end{array}$ \\
\hline Cor Aparente (PtCo) & 3890 & - \\
\hline Cor Real (PtCo) & 459,7 & $75 \mathrm{mg}$ Pt/L \\
\hline Turbidez (UNT) & 897 & $100 \mathrm{UNT}$ \\
\hline pH & 7,91 & $6,0-9,0$ \\
\hline DQO & 93,5 & - \\
\hline DBO (mg/L) & 37,66 & $10 \mathrm{mg} / \mathrm{L}$ \\
\hline Sólidos Totais (mg/L) & 862,33 & - \\
\hline \% Sólidos Totais Fixos & 88,88 & - \\
\hline $\begin{array}{l}\text { \% Sólidos Totais } \\
\text { Voláteis }\end{array}$ & 11,12 & - \\
\hline $\begin{array}{l}\text { Sólidos Suspensos Totais } \\
\text { (mg/L) }\end{array}$ & 705,33 & - \\
\hline $\begin{array}{l}\text { \% Sólidos Suspensos } \\
\text { Fixos }\end{array}$ & 67,23 & - \\
\hline $\begin{array}{l}\text { \% Sólidos Suspensos } \\
\text { Voláteis }\end{array}$ & 32,77 & - \\
\hline
\end{tabular}

Observando a Tabela 3 pode-se notar que as águas brutas utilizadas no processo de coagulação/ floculação, possuem alta cor aparente e turbidez.

A concentração de STV na água é pequena, apenas $11,12 \%$, indicando uma pequena fração de sólidos biodegradáveis na água bruta.

Os valores médios para a concentração dos metais na água bruta se encontram na Tabela 4 .

Tabela 4 - Concentração de metais na água bruta.

\begin{tabular}{|l|c|c|}
\hline PARÂMETROS & $\begin{array}{c}\text { Média } \\
(\mathrm{mg} / \mathrm{L})\end{array}$ & $\begin{array}{c}\text { Limite } \\
\text { CONAMA 357 } \\
\text { (Classe 3) mg/L }\end{array}$ \\
\hline Alumínio (Al) & 45,57 & 0,2 \\
\hline Arsênio $(\mathrm{As})$ & 0,389 & 0,033 \\
\hline Bário $(\mathrm{Ba})$ & 0,747 & 1,0 \\
\hline Cádmio $(\mathrm{Cd})$ & 0,0 & 0,01 \\
\hline Cobalto $(\mathrm{Co})$ & 0,052 & 0,2 \\
\hline Cobre $(\mathrm{Cu})$ & 0,165 & 0,013 \\
\hline Chumbo $(\mathrm{Pb})$ & 0,061 & 0,033 \\
\hline Cromo Total $(\mathrm{Cr})$ & 0,023 & 0,05 \\
\hline Ferro $(\mathrm{Fe})$ & 83,28 & 5,0 \\
\hline Manganês $(\mathrm{Mn})$ & 1,03 & 0,5 \\
\hline Níquel $(\mathrm{Ni})$ & 0,038 & 0,025 \\
\hline Prata $(\mathrm{Ag})$ & 0,005 & 0,05 \\
\hline Selênio $(\mathrm{Se})$ & 0,244 & 0,05 \\
\hline Zinco $(\mathrm{Zn})$ & 0,072 & 5,0 \\
\hline
\end{tabular}

Comparando com os limites estabelecidos pelo CONAMA 357, para corpos receptores classe 3, as concentraçóes de $\mathrm{Al}, \mathrm{As}, \mathrm{Ba}, \mathrm{Pb}, \mathrm{Cu}, \mathrm{Fe}$, $\mathrm{Mn}, \mathrm{Ni}$ e Se estáo acima do permitido. Alguns metais se destacam devido sua elevada concentração na água bruta, como o Alumínio e o Ferro (Tabela 4).

\section{LIXIVIADO}

O extrato lixiviado, dos lodos de PAC e Moringa, foram analisados frente a alguns parâmetros, apresentados nas tabelas 5 e 6 .

Tabela 5 - Concentração de metais do Lixiviado do lodo de PAC.

\begin{tabular}{|l|c|c|c|}
\hline PARÂMETROS & Média & Faixa & $\begin{array}{c}\text { Limite } \\
\text { NBR } \\
10004 \\
\text { Anexo F }\end{array}$ \\
\hline Alumínio (Al) & 15,007 & $\begin{array}{c}4,148- \\
29,753\end{array}$ & - \\
\hline
\end{tabular}




\begin{tabular}{|l|c|c|c|}
\hline Arsênio (As) & 0,543 & $\begin{array}{c}\text { n.d. - } \\
0,905\end{array}$ & 1,0 \\
\hline Bário (Ba) & 11,631 & $\begin{array}{c}1,223- \\
18,178\end{array}$ & 70,0 \\
\hline Cádmio (Cd) & 0,016 & $\begin{array}{c}0,007- \\
0,025\end{array}$ & 0,5 \\
\hline Chumbo (Pb) & 0,094 & $\begin{array}{c}0,007- \\
0,168\end{array}$ & 1,0 \\
\hline $\begin{array}{l}\text { Cromo Total } \\
\text { (Cr) }\end{array}$ & 0,028 & $\begin{array}{c}0,017- \\
0,035\end{array}$ & 5,0 \\
\hline Mercúrio (Hg) & n.d. & n.d. & 0,1 \\
\hline Prata (Ag) & 0.003 & $\begin{array}{c}\text { n.d. - } \\
0,005\end{array}$ & 5,0 \\
\hline Selênio (Se) & 0,700 & $\begin{array}{c}0,240- \\
0,852\end{array}$ & 1,0 \\
\hline
\end{tabular}

* n.d. = não detectado pelo aparelho.

Tabela 6 - Concentração de metais do Lixiviado do lodo de Moringa.

\begin{tabular}{|l|c|c|c|}
\hline PARÂMETROS & Média & Faixa & $\begin{array}{c}\text { Limite } \\
\text { NBR } \\
10004 \\
\text { Anexo F }\end{array}$ \\
\hline Alumínio (Al) & 0,309 & $\begin{array}{c}\text { n.d. - } \\
0,600\end{array}$ & - \\
\hline Arsênio (As) & 0,73 & $\begin{array}{c}0,265- \\
0,921\end{array}$ & 1,0 \\
\hline Bário (Ba) & 11,401 & $\begin{array}{c}8,145- \\
13,598\end{array}$ & 70,0 \\
\hline Cádmio (Cd) & 0,008 & $\begin{array}{c}0,004- \\
0,013\end{array}$ & 0,5 \\
\hline Chumbo (Pb) & 0,029 & $\begin{array}{c}\text { n.d. - } \\
0,049\end{array}$ & 1,0 \\
\hline Cromo Total (Cr) & 0,029 & $\begin{array}{c}\text { n.d. - } \\
0,033\end{array}$ & 5,0 \\
\hline Mercúrio (Hg) & 0,004 & $\begin{array}{c}\text { n.d. - } \\
0,018\end{array}$ & 0,1 \\
\hline Prata (Ag) & 0,011 & $\begin{array}{c}\text { n.d. - } \\
0,021\end{array}$ & 5,0 \\
\hline Selênio (Se) & 0,249 & $\begin{array}{c}\text { n.d. - } \\
0,587\end{array}$ & 1,0 \\
\hline
\end{tabular}

* n.d. = não detectado pelo aparelho.

Os resultados obtidos pela análise do extrato lixiviado dos lodos estudados, encontram-se de acordo com a respectiva Norma Técnica, não excedendo os limites máximos estabelecidos, indicando que estas amostras de lodo não representam um resíduo com características de periculosidade (resíduo Classe I). Logo ambos os lodos são classificados como resíduos Classe II.

Apesar do $\mathrm{Al}$ não ser um parâmetro estabelecido pela norma para este tipo de análise, neste caso é de suma importância devido ao tipo de coagulante utilizado no tratamento da água bruta. Pode-se observar que a concentraçáo de alumínio em todas as amostras de PAC é muito alta quando comparado com as concentraçóes de alumínio nas amostras de Moringa.

\section{SOLUBILIZADO}

As Tabelas 7 e 8 mostram os resultados das análises dos metais do extrato solubilizado conforme estabelecido pela norma ABNT NBR 10006.

Tabela 7 - Concentração de metais do Solubilizado do lodo de PAC.

\begin{tabular}{|l|l|c|c|}
\hline PARÂMETROS & Média & Faixa & $\begin{array}{c}\text { Limite } \\
\text { NBR } \\
\text { Anexo G }\end{array}$ \\
\hline Alumínio (Al) & 0,389 & $\begin{array}{c}\text { n.d. - } \\
0,872\end{array}$ & 0,2 \\
\hline Arsênio (As) & 0,961 & $\begin{array}{c}0,825- \\
1,069\end{array}$ & 0,01 \\
\hline Bário (Ba) & 5,053 & $\begin{array}{c}4,719- \\
5,387\end{array}$ & 0,7 \\
\hline Cádmio (Cd) & 0,002 & $\begin{array}{c}\text { n.d. - } \\
0,005\end{array}$ & 0,005 \\
\hline Chumbo (Pb) & 0,006 & $\begin{array}{c}\text { n.d. - } \\
0,014\end{array}$ & 0,001 \\
\hline Cobre (Cu) & 0,024 & $\begin{array}{c}\text { n.d. - } \\
0,050\end{array}$ & 2,0 \\
\hline Cromo Total (Cr) & 0,026 & $\begin{array}{c}0,025- \\
0,027\end{array}$ & 0,05 \\
\hline Ferro(Fe) & 1,317 & $\begin{array}{c}0,361- \\
2,372\end{array}$ & 0,3 \\
\hline Manganês (Mn) & 9,736 & $\begin{array}{c}0,468- \\
19,636\end{array}$ & 0,1 \\
\hline Mercúrio (Hg) & n.d. & n.d. & 0,001 \\
\hline Prata (Ag) & n.d. & n.d. & 0,05 \\
\hline Selênio (Se) & 0,444 & $\begin{array}{c}0,229- \\
0,740\end{array}$ & 0,01 \\
\hline Sódio (Na) & 16,562 & $\begin{array}{c}13,037- \\
21,432\end{array}$ & 200 \\
\hline Zinco (Zn) & 0,295 & $\begin{array}{c}0,045- \\
0,545\end{array}$ & 5,0 \\
\hline
\end{tabular}

* n.d. = não detectado pelo aparelho.

Tabela 8 - Concentração de metais do Solubilizado do lodo de Moringa. 


\begin{tabular}{|l|c|c|c|}
\hline PARÂMETROS & Média & Faixa & $\begin{array}{c}\text { Limite } \\
\text { NBR } \\
\text { Anexo G }\end{array}$ \\
\hline Alumínio (Al) & 0,252 & $\begin{array}{c}\text { n.d. - } \\
0,531\end{array}$ & 0,2 \\
\hline Arsênio (As) & 1,062 & $\begin{array}{c}0,783- \\
1,207\end{array}$ & 0,01 \\
\hline Bário (Ba) & 9,621 & $\begin{array}{c}9,395- \\
9,846\end{array}$ & 0,7 \\
\hline Cádmio (Cd) & 0,002 & $\begin{array}{c}\text { n.d. - } \\
0,005\end{array}$ & 0,005 \\
\hline Chumbo (Pb) & 0,01 & $\begin{array}{c}\text { n.d. - } \\
0,025\end{array}$ & 0,001 \\
\hline Cobre (Cu) & 0,036 & $\begin{array}{c}\text { n.d. - } \\
0,098\end{array}$ & 2,0 \\
\hline Cromo Total (Cr) & 0,029 & $\begin{array}{c}0,027- \\
0,031\end{array}$ & 0,05 \\
\hline Ferro(Fe) & 4,091 & $\begin{array}{c}0,282- \\
10,066\end{array}$ & 0,3 \\
\hline Manganês (Mn) & 27,250 & $\begin{array}{c}18,394- \\
40,171\end{array}$ & 0,1 \\
\hline Mercúrio (Hg) & n.d. & n.d. & 0,001 \\
\hline Prata (Ag) & n.d. & $\begin{array}{c}\text { n.d. } \\
0,198- \\
0,649\end{array}$ & 0,05 \\
\hline Selênio (Se) & 0,434 \\
\hline Sódio (Na) & 9,032 & $\begin{array}{c}7,086- \\
10,554\end{array}$ & 200 \\
\hline Zinco (Zn) & 1,548 & $\begin{array}{c}0,065- \\
3,030\end{array}$ & 5,0 \\
\hline
\end{tabular}

* n.d. = não detectado pelo aparelho.

A análise do extrato obtido pela execução dos ensaios de solubilização, indica solubilização dos elementos Al, As, Ba, Pb, Fe, Mn e Se acima do limite máximo estabelecido neste ensaio, tanto no lodo proveniente do uso de coagulante químico quanto natural. Logo, ambos os lodos são classificados, segundo a norma técnica, como um resíduo Classe IIA, Não perigoso - Não Inerte.

Os demais parâmetros quantificados no ensaio de solubilização se encontram dentro dos limites estabelecidos, não excedendo as concentraçôes máximas para o extrato solubilizado, estabelecidas pela norma técnica ABNT NBR 10.004, para este ensaio.

Mesmo com o uso de um coagulante natural o lodo pode possuir uma alta concentração de metais pesados em sua composição, pois estes possivelmente são oriundos da água bruta utilizada no tratamento.

De acordo com estudos realizados por Guerra e Angelis (2005), o lodo proveniente dos decantadores da ETA II e ETA Capim Fino, segundo a norma ABNT NBR 10.004, são classificados como um resíduo Classe IIA (não perigoso-não inerte).

Araújo (2006) diz que os testes para obtenção do extrato solubilizado, a partir do lodo da ETA Barreiros, enquadram esses resíduos como resíduo sólido Classe IIA - não inerte, evidenciando os potenciais riscos que eles representam para o meio aquático e para os solos onde são dispostos. Os metais que não se enquadram dentro dos limites para o extrato solubilizado foram $\mathrm{Al}, \mathrm{Fe}$ e $\mathrm{Mn}$.

\section{CONCLUSÁO}

Após avaliação dos resultados dos ensaios de Lixiviação pode-se observar que todos os valores referentes à análise de metais se encontram dentro do limite máximo estabelecido pela norma ABNT NBR 10.004 (2004), indicando que estas amostras de lodo não representam um resíduo com características de periculosidade (resíduo Classe I). Logo ambos os lodos são classificados como resíduos Classe II.

Já nos ensaios de Solubilização, os metais $\mathrm{Al}, \mathrm{As}, \mathrm{Ba}, \mathrm{Pb}, \mathrm{Fe}, \mathrm{Mn}$ e Se estão acima do limite máximo estabelecido pela norma, logo, conclui-se que os lodos de PAC e Moringa caracteriza-se como um resíduo Classe II A, Não perigoso - Não inerte. Portanto deve ser disposto de modo adequado, de forma a não causar danos ao meio ambiente e aos seres humanos.

Mesmo com o uso de um coagulante natural o lodo pode possuir uma alta concentraçáo de metais pesados em sua composição, pois estes possivelmente são oriundos da água bruta utilizada no tratamento, gerando assim um lodo Classe II A, Não perigoso - Não inerte. Ressaltando que neste experimento foram utilizadas somente águas de alta cor e turbidez.

\section{REFERÊNCIAS}

ABNT NBR 10004. Associação Brasileira de Normas Técnicas. Resíduos sólidos - Classificação. 2a Ed. 2004.

ABNT NBR 10005. Associação Brasileira de Normas Técnicas. Procedimento para obtenção de extrato lixiviado de resíduos sólidos. 2a $\mathrm{Ed} .2004$. 
ABNT NBR 10006. Associação Brasileira de Normas Técnicas. Procedimento para obtenção de extrato solubilizado de resíduos sólidos. $2^{\mathrm{a}} \mathrm{Ed} .2004$.

Achon, C. L.; Barroso, M. M.; Cordeiro, J. S. Leito de drenagem: Sistema natural para redução de volume de lodo de estação de tratamento de água. Engenharia sanitária ambiental.Vol.13 - No 1 jan/mar 2008, 54-62. 2008.

APHA, AWWA \& WEF. Standard Methods for the Examination of Water and Wastewater., Clesceri, L. S.; Greenberg, A.E.; Eaton A.D., 20th Ed., Washington-USA, 1998.

Araújo, A. P. M. Avaliação operacional e características do lodo gerado na indústria da água do litoral sul de Pernambuco. Dissertação de Mestrado, Programa de Pós Graduação em Engenharia Civil, Universidade Federal de Pernambuco - UFPE, Recife - PE, 2006.

Bongiovani, M. C.; Konradt-Moraes, L. C.; Bergamasco, R.; Lourenço, B. S. S.; Tavares, C. R. G. Os benefícios da utilização de coagulantes naturais para a obtençâo de água potável. Acta Scientiarum. Technology Maringá, v. 32, n. 2 p. 167-170, 2010 .

Botero, W. G.; Santos, A.; Oliveira, L. C.; Rocha, J. C. Caracterização de lodo gerado em estaçôes de tratamento de água: perspectivas de aplicação agrícola. Química Nova, vol. 32, no 8, p. 2018 - 2022, 2009.

Cardoso, K. C.; Bergamasco, R; Cossich, E. S.; Konradt-Moraes, L. C. Otimização dos tempos de mistura e decantação no processo de coagulação/floculação da água bruta por meio da Moringa oleifera Lam. Acta Sci. Tech. Maringá, v. 30, n. 2, p. 193198, 2008.
Carvalho, M. J. H. Uso de coagulantes naturais no processo de obtenção de água potável. Dissertação de Mestrado, Engenharia Urbana, Universidade Estadual de Maringá - UEM, Maringá, 2008.

Davino, F. Tecnologia de Tratamento de Água Água na Indústria. Rio de Janeiro: Almeida Neves., 1976.

Guerra, R. C.; Angelis, D. F. D. Classificação e biodegradaçáo de lodo de estaçóes de tratamento de água para descarte em aterro sanitário. Arq. Inst. Biol., São Paulo, v.72, n.1, p.87-91, 2005.

Hoppen, C.; Portella, K. F.; Joukoski, A.; Trindade, E. M.; Andreóli, C. V. Uso de lodo de estação de tratamento de água centrifugado em matriz de concreto de cimento portland para reduzir o impacto ambiental. Química Nova, Vol. 29, no 1, pg. 7984. 2006.

Madrona, G. S.; Serpelloni, G. B.; Vieira, A. M. S.; Nishi, L.; Cardoso, K. C.; Bergamasco, R. Study of the Effect of Saline Solution on the Extraction of the Moringa oleifera Seed's Active Component for Water Treatment. Water Air Soil Pollut, v. 211, pg. 409-415. 2010.

Monaco, P. A. V. L.; Matos, A. T.; Ribeiro, I. C. A.; Nascimento, F. S.; Sarmento, A. P. Utilizaçâo de extrato de semente de moringa como agente coagulante no tratamento de água para abastecimento $e$ águas residuárias. Revista Ambiental e Água - An interdisciplinary Journal Applied Science: v. 5, n. 3, 2010.

Reis, E. L. T.; Cotrim, M. E. B.; Rodrigues, C.; Pires, M. A. F.; Bertrame-Filho, O.; Rocha, S. M.; Cutolo, S. A. Identificação da influência do descarte de lodo de estaçôes de tratamento de água. Quimíca Nova, Vol. 30, No. 4, 865-872, 2007.

Artigo submetido em 20/11/2011, aceito em 17/05/2012 